\title{
Chromatin-Based Regulation of Plant Root Development
}

\author{
Dong-Hong Chen ${ }^{1 * t}$, Yong Huang ${ }^{2 \dagger}$, Changhua Jiang ${ }^{3+}$ and Jin-Ping $\mathrm{Si}^{1 *}$ \\ ${ }^{1}$ State Key Laboratory of Subtropical Silviculture, SFGA Engineering Research Center for Dendrobium Catenatum, Zhejiang \\ A\&F University, Hangzhou, China, ${ }^{2}$ Key Laboratory of Education Department of Hunan Province on Plant Genetics and \\ Molecular Biology, Hunan Agricultural University, Changsha, China, ${ }^{3}$ Shanghai Botanical Garden, Shanghai, China
}

\section{OPEN ACCESS}

Edited by:

José Manuel Pérez-Pérez,

Universidad Miguel Hernández de

Elche, Spain

Reviewed by:

Hirotomo Takatsuka,

Nara Institute of Science and Technology (NA/ST), Japan

Crisanto Gutierrez,

Consejo Superior de Investigaciones

Científicas (CS/C), Spain

*Correspondence:

Dong-Hong Chen donghong.chen@zafu.edu.cn Jin-Ping $S$ Issjp@163.com

these authors have contributed equally to this work

Specialty section

This article was submitted to Plant Evolution and Development,

a section of the journal

Frontiers in Plant Science

Received: 12 July 2018 Accepted: 26 September 2018

Published: 16 October 2018

Citation:

Chen D-H, Huang Y, Jiang C and Si J-P (2018) Chromatin-Based

Regulation of Plant Root Development.

Front. Plant Sci. 9:1509.

doi: 10.3389/fp/s.2018.01509
Plant is endowed with sessile habit and nutrient acquisition mainly through the root organ, which also provides an excellent model to study stem cell fate and asymmetric division due to well-organized cell layers and relatively simple cell types in root meristem. Besides genetic material DNA wrapped around histone octamer, chromatin structure determined by chromatin modification including DNA methylation, histone modification and chromatin remodeling also contributes greatly to the regulation of gene expression. In this review, we summarize the current progresses on the molecular mechanisms of chromatin modification in regulating root development.

Keywords: chromatin structure, histone modification, Polycomb, TrxG, SDG family, chromatin remodeling, root development, stem cell niche

\section{INTRODUCTION}

The root system constitutes the underground world of a plant, and it takes charge of nutrient and water supply for the whole plant under normal and stress environments. The developmental status of the root system directly determines the plant survival and performance of leaves, stems, flowers, fruits, and seeds, which are closely related to animal and human life. Compared with the aerial part, the building unit of a root system is simple and mainly consists of primary and lateral roots (LRs) without substantial difference in appearance. An intact root system is derived from the tiny root apical meristem (RAM). Proliferation and differentiation of RAM give rise to different types of root cells and tissues.

Transcription factors combined with phytohormones, small signaling molecules, and miRNAs play an essential role in regulating the stem cell fate and RAM maintenance during root development (Drisch and Stahl, 2015). Root development-controlled genes are stored in the genomes of all cells from the same plant, but their transcripts are only expressed in specific root cells and tissues. This kind of spatiotemporal divergence of gene expression is closely associated with the alteration in chromatin structure, which determines the transcriptional accessibility to DNA in response to internal and external stimuli (Narlikar et al., 2002). The accessible (active/open) or inaccessible (repressive/close) state of chromatin structure is mainly accomplished by three types of chromatin-based regulation, namely, DNA methylation, ATP-dependent chromatin remodeling and histone covalent modification.

\section{ROOT ORGANOGENESIS IN ARABIDOPSIS}

Roots have two fundamental functions: anchorage to the substrate and uptake of water and nutrients in almost all plants. However, in specific species, root have evolved some novel roles, such as physical support, photoassimilate storage, metabolite biosynthesis, and interactions with the rhizosphere (Zhu et al., 2011). Roots are divided into primary roots, LRs, 
and adventitious roots based on position origin. Primary root initiation in the model plant Arabidopsis can be traced back to embryogenesis. Hypophysis, the uppermost suspensor cell incorporates into the embryo proper at an early globular stage. This cell divides asymmetrically, generating an upper lens-shaped quiescent center (QC) cell and a lower cell (columella initial), and finally giving rise to RAM (De Smet et al., 2008). RAM is located at the primary root tip, and it is responsible for the establishment of a post-embryonic root system. In Arabidopsis, RAM undergoes asymmetrical cell division to give rise to selfrenewal and production of various cell types, which further expand and differentiate to form elongation and maturation/root hair zones. RAM is composed of the proliferation domain (PD) with high mitotic activity and the transition domain (TD) with low mitotic activity along the longitudinal axis (Ivanov and Dubrovsky, 2013). In the PD region, the stem cell niche (SCN) is located at the center, which consists of a small group of mitotically less active quiescent center (QC) cells surrounded with four types of stem cells, namely, columella initial/stem cell (CSC), epidermal cell and lateral root cap (Epi/LRC) initial, cortex/endodermis initial (CEI), and stele initial (Scheres et al., 1994). At the proximal part, CEIs divide periclinally, producing two types of ground tissues, namely, cortex and endodermis. Stele initials produce a vascular cylinder. At the distal part, Epi/LRC initials sequentially divide anticlinally, and periclinally divisions, thereby generating epidermis (Epi) and LRC. Asymmetric divisions of CSCs experience directly generate differentiated columella cells with starch granules for gravity sensing (Dolan et al., 1993). LR branching from the parent root is crucial for maximizing the function of the root system. In angiosperms, LRs are usually derived from the pericycle cells of parent roots. However, endodermis cells contribute to LR formation in some monocots (Malamy and Benfey, 1997). In Arabidopsis, the organogenesis of a LR can be divided into eight stages based on specific anatomical characteristics and cell divisions (Malamy and Benfey, 1997). In summary, LRs are initiated when single or pairs of pericycle founder cells across the xylem poles undergo several rounds of asymmetric anticlinal divisions, creating a single layered primordium containing up to 10 small cells (stage I). Such cells divide periclinally and form an inner layer and outer layer (stage II). After a series of anticlinal and periclinal divisions, the LR primordium (LRP) gradually acquires a dome shape (stages III to VII) and eventually protrudes from the parent root (stage VIII) (Malamy and Benfey, 1997; Casimiro et al., 2001; Dubrovsky et al., 2001; Peret et al., 2009). Adventitious roots indicate shoot-born roots from undifferentiated and reprogrammed cells, which are often associated with vascular tissues in response to developmental and environmental stimuli. adventitious root emergence shares many developmental characteristics with LR formation, but it requires a specific set of signaling components (Verstraeten et al., 2014). Additionally, root hairs in soil strengthen the absorption capability of roots. A root hair is derived from a specific root epidermal cell, and its development has four phases: cell fate specification of trichoblasts and atrichoblasts, root hair initiation, tip growth and maturation (Gilroy and Jones, 2000).

\section{CHROMATIN STRUCTURE AND CHROMATIN MODIFIERS}

Nucleosome, the fundamental building unit of chromatin, is composed of $\sim 146$ bp of DNA wrapped around a histone octamer with two copies of each of the core histones H2A, H2B, H3, and H4 (Luger et al., 1997). Nucleosomes are interconnected by linker DNAs and fixed by histones $\mathrm{H} 1$, which are involved in higher-order chromatin structure compaction. The status of DNA packaging into chromatin affects the accessibility of DNA by regulatory factors and the output of genomic information at specific spatio-temporal developmental contexts. The chromatin structure can be regulated by chromatin remodelers, which disrupt non-covalent DNA-histone interactions and histone modifiers which catalyze or remove covalent linkages of chemical groups from histones (Li et al., 2007). ATP-dependent chromatin remodeling enzymes alter the chromatin structure by adjusting the density or location of nucleosomes on the target DNA locus and catalyze the incorporation of histone variants using ATP hydrolysis energy (Narlikar et al., 2013). On the basis of phylogenetic analysis, chromatin remodelers in plants can be divided into 18 classes, and each class harbors a common catalytic ATPase domain and class-specific domains, such as well-characterized PHD, chromodomain, bromodomain, SANT, and RING domain (Knizewski et al., 2008; Hu et al., 2013). By contrast, both freely stretched tails and core regions in the histone octamer may undergo various post-translational modifications, such as methylation, acetylation, phosphorylation, ubiquitination, citrullination, hydroxylation, O-GlcNAcylation, and ADP-ribosylation (Huang et al., 2014; Lawrence et al., 2016). The dynamic balances of distinct histone modifications in vivo are maintained by specific enzymes ("writers" and "erasers"). For instance, active marker histone acetylation and repressive marker histone deacetylation are catalyzed by histone acetyltransferases (HATs) and histone deacetylases (HDACs), respectively (Eberharter and Becker, 2002). Histone modification either directly influences the chromatin structure by altering the charge of histone or acts as an anchorage site that is recognized by "readers," which recruit other effectors to regulate gene expression. Specific histone modifications play fixed roles in transcription. For example, H3K4 trimethylation (H3K4me3) and H3K36me3 are associated with transcriptional activation, whereas the trimethylation of lysine 27 on histone H3 (H3K27me3) and H3K9me2 are associated with transcriptional repression (Pontvianne et al., 2010).

Chromatin modifiers normally act as part of large multimeric complexes to exert precise biological functions. These modifiers are often classified into two groups with antagonistic roles, the polycomb group $(\mathrm{PcG})$ proteins associated with repressive genes and the trithorax group (TrxG) proteins associated with active genes (Schuettengruber and Cavalli, 2009; Kohler and Hennig, 2010). In animals and plants, PcG proteins mainly constitute two evolutionarily conserved complexes, namely, polycomb repressive complex 1 (PRC1) and PRC2. On the basis of the classical model in animals, PRC2 complex catalyzes $\mathrm{H} 3 \mathrm{~K} 27 \mathrm{me} 3$ at the target gene chromatin, and PRC1 recognizes 
this repressive mark and catalyzes monoubiquitination of lysine 119 on histone H2A (H2Aub1) (Schuettengruber et al., 2007). In Arabidopsis, PRC2 core subunits contain three Drosophila $E(z)$ homologs (CLF, SWN, and MEA), three Su(z)12 homologs (EMF2, FIS2 and VRN2), a single ESC homolog (FIE), and five p55 homologs (MSI1-MSI5). PRC1 core subunits consist of two RING1 homologs (AtRINGla/b), three Psc homologs (AtBMI1a/b/c), a Pc equivalent (LHP1), and a plant-specific component EMF1, without the Ph counterpart (Chen D. H. et al., 2016; Forderer et al., 2016).

In addition, DNA methylation is another kind of chromatinbased modification that occurs on the DNA-specific cytosine residues, such as $\mathrm{CG}, \mathrm{CHG}$, and $\mathrm{CHH}$ contexts (where $\mathrm{H}=$ A, T, or C; Law and Jacobsen, 2010). DNA methylation is widely involved in different biological programs and responses to environmental stimuli (Jullien et al., 2012; Zhang et al., 2018). However, investigation on the function of DNA methylation in root development are limited. A comparison of distinct cell types in RAM reveals the highest level of DNA methylation exists in columella root cap (Kawakatsu et al., 2016). Thus, this review emphasizes the role and regulation of histone modifiers and chromatin remodeling ATPases in root development, especially in Arabidopsis (Table 1).

\section{HISTONE ACETYLATION AND DEACETYLATION IN ROOT DEVELOPMENT}

The homeostasis of histone acetylation in vivo is dynamically maintained by HATs and HDACs (Shahbazian and Grunstein, 2007). Arabidopsis possesses 12 HATs and 18 HDACs, in which HATs are categorized into four families (GNAT/HAG, MYST/HAM, p300/CBP/HAC, and TAFII250/HAF), and HDACs are composed of three classes (RPD3, HDA1, and SIR2) homologous to yeast counterparts, and a plant-specific class (HD2; Pandey et al., 2002; Hollender and Liu, 2008).

Histone acetylation plays a key role in regulating the cellular patterning of the root epidermis. The single-layered epidermis in Arabidopsis root harbors two cell types, namely, trichoblast/hair cell $(\mathrm{H})$ and atrichoblast/non-hair cell $(\mathrm{N})$ in an alternative arrangement, providing a well-characterized system for studying the relationship between root epidermal cell fate decision and positional cue from underlying cortical cells (Caro et al., 2007). Treatment with HDAC inhibitor Trichostatin A (TSA) induces $\mathrm{H}$ development at $\mathrm{N}$ positions in the root epidermis through hyperacetylation of histones $\mathrm{H} 3$ and $\mathrm{H} 4$ and ectopic expression of patterning genes CPC, GL2, and WER (Xu et al., 2005). However, the mutation and overexpression of histone deacetylase HDA18 result in the conversion of cells at the $\mathrm{N}$ position to $\mathrm{H}$ fate; HDA18 is required for the establishment of root epidermal cell patterning through regulating histone acetylation levels of several kinase loci but not pattern genes (Xu et al., 2005; Liu et al., 2013). Similarly, HDA6 depletion leads to ectopic $\mathrm{H}$ cells at the $\mathrm{N}$ positions; HDA6 affects cellular patterning by altering the status of histone acetylation at the promoter regions of pattern genes ETC1 and GL2
(Li et al., 2015). Phenotypic analysis of all available HDAC and HAT single mutants further shows three HDACs (HDA6, HDA18, and HDA19) and two HATs (GCN5 and HAF2) exhibit altering cellular patterns in root epidermis (Chen W. Q. et al., 2016).

Histone acetylation is important for root growth and morphogenesis. HDAC inhibitors repress primary root elongation and LR emergence via regulation of $26 \mathrm{~S}$ proteasomemediated degradation of PIN1 and alteration in auxin distribution in Arabidopsis (Nguyen et al., 2013). Furthermore, TSA treatment affects the expression of S-phase kinaseassociated protein 2B (SKP2B), which acts as an F-box protein involved in the regulation of the stability of cyclin-dependent kinase inhibitor KRP1 (Ren et al., 2008). SKP2B promoter is regulated by histone $\mathrm{H} 3$ acetylation on $\mathrm{K} 9$ and $\mathrm{K} 14$ in an auxin- and IAA14/SLR-dependent manner, and $s k p 2 b$ mutant displays increased root elongation and LR emergence (Manzano et al., 2012). On the other hand, TSA can rescue LR formation in the gain-of-function mutant $s l r-1$, which has stabilized mutant SOLITARY-ROOT (SLR)/IAA14 (mIAA14) protein with enhanced inhibiting capacity on the downstream targets ARF7/19 (Fukaki et al., 2006). In rice, overexpression of a class I-type (RPD3-like) histone deacetylase OsHDAC1 accelerates root growth rate in seedlings (Jang et al., 2003). Chromatin immunoprecipitation (ChIP) assay showed that OsHDAC1 represses the key downstream target OsNAC6 by binding to the OsNAC6 promoter and deacetylating $\mathrm{K} 9, \mathrm{~K} 14$, and $\mathrm{K} 18$ on $\mathrm{H} 3$ and $\mathrm{K} 5, \mathrm{~K} 12$, and $\mathrm{K} 16$ on $\mathrm{H} 4$. Consistently, OsNAC6 knockout seedlings have a root phenotype similar to OsHDAC1 overexpression seedlings (Chung et al., 2009). In Populus, HDACs are required for de novo organogenesis and normal development of roots, and TSA treatment delays the regeneration of adventitious roots and inhibits the growth of primary roots, similar to Arabidopsis (Ma et al., 2016). LDL1/SWP1 encodes a homolog of human LYSINE-SPECIFIC DEMETHYLASE1 (LSD1), which is a core component of several HDAC corepressor complexes (Humphrey et al., 2001; Hakimi et al., 2002; Jiang et al., 2007). LDL1/SWP1 participates in regulating root elongation by suppressing the root primordiumspecific gene LRP1 via histone deacetylation. Similar to the phenotype of LRP1 overexpression, Loss of function of $L D L 1$ leads to histone hyperacetylation and elevated expression of $L R P 1$, thereby increasing root elongation (Krichevsky et al., 2009).

Histone acetylation is required for RAM maintenance and cell proliferation and differentiation. TSA treatment causes aberrant SCN cell divisions and formation of an extra layer of ground tissue (premature middle cortex) in roots (Cui and Benfey, 2009). Histone acetyltransferase GENERAL CONTROL NON-DEREPRESSIBLE 5 (GCN5) and the associated factor ALTERATION/DEFICIENCY IN ACTIVATION 2b (ADA2b) act in the PLT pathway and mediate the proliferation of transit-amplifying cells during root development (Vlachonasios et al., 2003; Kornet and Scheres, 2009). However, GCN5, but not ADA2b, is involved in root SCN maintenance, and PLT2 overexpression restores the SCN defect of gcn 5 mutants. Therefore, ADA2b and GCN5 have both similar and distinct 
TABLE 1 | Chromatin modifiers in Arabidopsis.

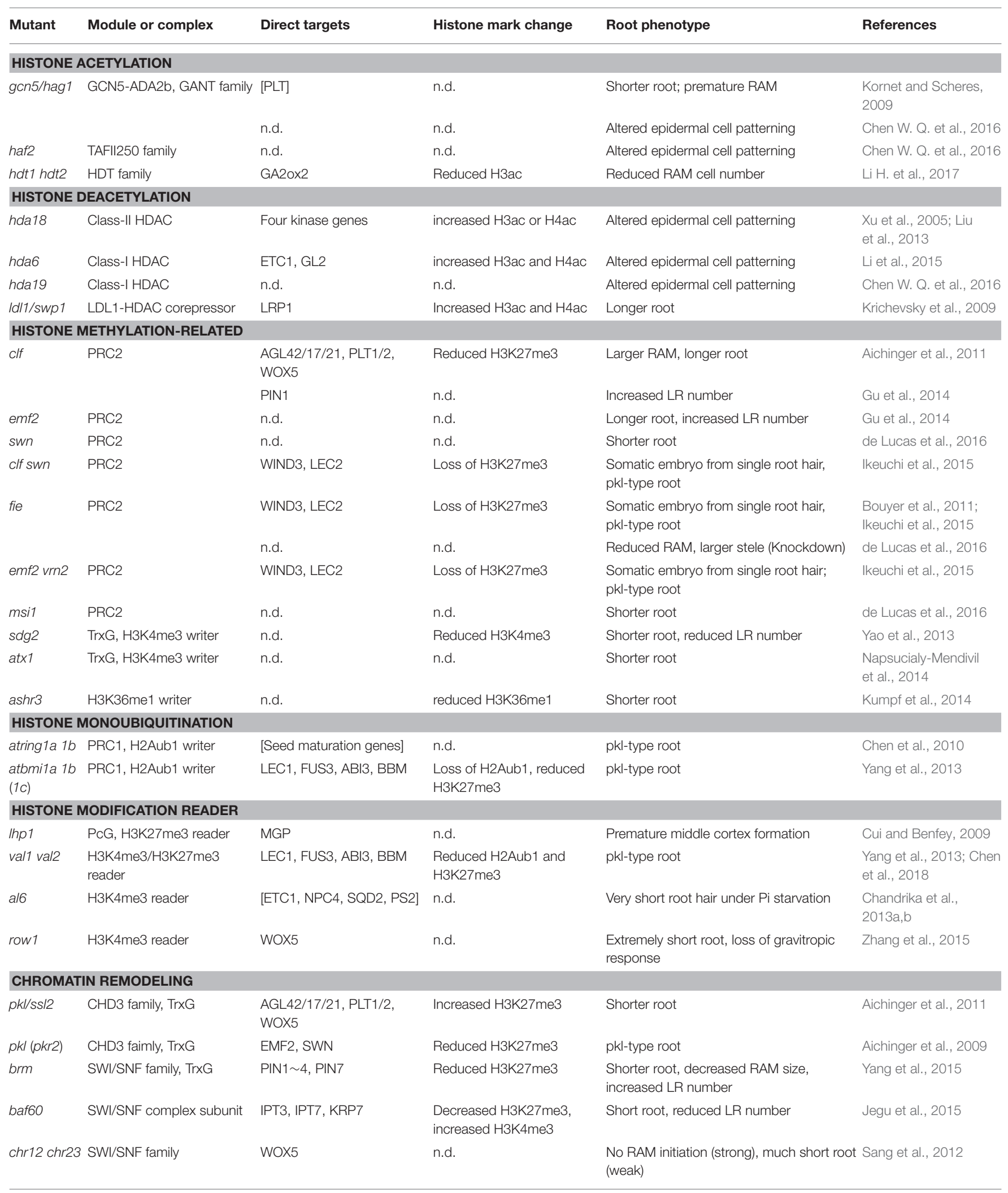

[Putative targets lacking evidence of direct binding. n.d., not detected. 
functions. HDT1/2 determine the number of RAM cells by influencing the transition from cell division to expansion. Downregulation of $H D T 1 / 2$ in $h d t 1,2 i$ causes earlier transition from cell division to expansion, reduced the number of RAM cells. Furthermore, HDT1/2 repress the expression of GA2ox2 in the RAM and elongation zone through histone deacetylation of GA2ox2, thereby increasing the expression of $h d t 1,2 i$ plants. Moreover, GA2ox2 overexpression in RAM phenocopies $h d t 1,2 i$ mutants, whereas GA2ox2 knockout partially rescues $h d t 1,2 i$ root defects (Li H. et al., 2017). WUSCHEL-related homeobox (WOX) transcription factors are the master regulators that maintain stem cell fate in different meristem types, such as shoot and root meristems, vascular cambia, and leaf marginal meristems (Aichinger et al., 2012). WOX5 is a mobile organizer signal that moves from the QC to the neighboring CSCs, and recruits Groucho co-repressors TOPLESS/TOPLESSRELATED (TPL/TPR) and HISTONE DEACETYLASE 19 (HDA19) to induce histone deacetylation and repress the differentiation factor CYCLING DOF FACTOR 4 (CDF4), resulting in formation of decreased CDF4 protein gradient from differentiated columella, CSCs to QC, which is opposite to the WOX5 protein gradient and permits the exit of stem cell descendants from the stem cell state ( $\mathrm{Pi}$ et al., 2015). In rice, OsWOX11 stimulate meristem cell proliferation in crown roots via recruitment of the ADA2-GCN5 histone acetyltransferase module to activate downstream target genes (Zhou et al., 2017).

Histone acetylation is involved in the regulation of root development in response to environmental stress. In maize seedlings, exposure to salt stress results in shortening and swelling of roots due to reduced meristematic activity and enlargement of stele tissues and cortex cells in the elongation zone (Li et al., 2014). $\mathrm{NaCl}$ treatment increases the expression of histone acetyltransferases $Z m H A T B$ and $Z m G C N 5$ and the global acetylation levels of $\mathrm{H} 3 \mathrm{~K} 9$ and $\mathrm{H} 4 \mathrm{~K} 5$; consistently, cell wallrelated genes $Z m E X P B 2$ and $Z m X E T 1$ are upregulated through the increased deposition of $\mathrm{H} 3 \mathrm{~K} 9$ acetylation on their promoter and coding regions (Li et al., 2014). Thus, histone acetylation is involved in the rapid regulation of the expression of cell wall-related genes, which mediate cell enlargement and reduce salinity-induced ionic toxicity.

\section{HISTONE METHYLATION AND PRC2 COMPLEX IN ROOT DEVELOPMENT}

Histone methylation is mainly catalyzed by evolutionarily conserved SET domain-containing proteins of the SETDOMAIN GROUP (SDG) family (Ng et al., 2007). The Arabidopsis genome contains 49 SDG members, which can be divided into seven classes with distinct functions, $\mathrm{E}(\mathrm{z})$ homologs for H3K27 methylation, ASH1 homologs for H3K36 methylation, TRX homologs for H3K4 methylation, Su(var) homologs, S-ET proteins with an interrupted SET domain, and RBCMT for non-histone proteins (Ng et al., 2007; Pontvianne et al., 2010). Among these classes, $\mathrm{E}(\mathrm{z})$ homologs constitute the key catalytic subunits in multiple PRC2 complexes, involved in the regulation of cell fate transition and cell identity maintenance.
SDG family and histone methylation are essential for RAM maintenance and LR formation. SDG2 is the major H3K4 methyltransferase in vivo (Berr et al., 2010), and it is required for SCN maintenance in primary roots and SCN establishment in LRs. Depletion of SDG2 results in drastically reduced H3K4me3 levels and loss of auxin gradient maximum in root SCN cells. Additionally, SDG2 is involved in protecting genome integrity in SCN, and the $s d g 2$ mutant displays elevated DNA damage (Yao et al., 2013). Another H3K4 methyltransferase Arabidopsis homolog of trithorax1 (ATX1/SDG27) is implicated in SCN maintenance and cell patterning during root development; the loss-of-function of mutant atx1-1 reveals the retarded growth of primary roots due to reduced RAM activity, and disorganized cell patterns due to loss of coordination between cell division and proliferation (Napsucialy-Mendivil et al., 2014). ATX1 is also required for LR initiation and morphogenesis; the atx11 mutant undergoes additional anticlinal divisions in stageI LRP, asymmetric development, and delayed LR emergence (Napsucialy-Mendivil et al., 2014). The ASHR3/SDG4 that acts as an H3K36 monomethyltransferase is expressed in SCN and is required for the synchronization of replication and cell divisions in the root proximal meristematic zone (Kumpf et al., 2014). In comparison with the synchronous switch from mitotic cell cycle to endoreduplication in WT root meristems, the mutations of ASHR3 gene disrupt the coordinated pattern of DNA replication and cell division and accelerates QC division rate (Kumpf et al., 2014). ASHR3 is the direct downstream target of $\mathrm{E} 2 \mathrm{Fa} / \mathrm{E} 2 \mathrm{Fb}$ transcription factors which control the G1-to-S-phase transition, thereby confirming the role of ASHR3 in the regulation of cell division (Kumpf et al., 2014). In addition, PHD-containing protein REPRESSOR OF WUSCHEL1 (ROW1) is an H3K4me3 reader that is required for QC identity maintenance and SCN development by specifically recognizing the H3K4me3 mark of the WOX5 promoter to repress its transcription in the proximal root meristem. Mutation in wox5 can rescue the extremely short root phenotype of row1 (Zhang et al., 2015).

CLF is the major $\mathrm{H} 3 \mathrm{~K} 27 \mathrm{me} 3$ writer in plants and it is a catalytic subunit in PRC2 complex. full catalytic activity of CLF requires the integrity of $\mathrm{PRC} 2$ complex due to the almost entire loss of H3K27me3 mark in other PRC2 subunit mutants, such as emf2 vrn2 and fie (Schubert et al., 2006; Bouyer et al., 2011; Lafos et al., 2011). PRC2 core components CLF, SWN, EMF2, VRN2, FIE, and MSI1 but not endosperm-specific MEA are implicated in root meristem development and vascular cell proliferation and specification (de Lucas et al., 2016). The swn mutant has reduced root elongation without affecting meristem size, whereas clf-29 display slightly elongated primary roots and large root meristems (Aichinger et al., 2011; de Lucas et al., 2016), clf-28 swn-7 and fie mutants have substantially shortened roots with small meristems and increased number of cells in the vascular cylinder (de Lucas et al., 2016). Silencing of MSI1 specifically in the root vascular cylinder conferred by WOLp::amiRNA_MSI1 construction leads to moderately decreased root growth and extremely small root meristems (de Lucas et al., 2016). Similar to the clf mutant phenotype, the knockdown of EMF2 results in long primary roots and curly leaves (Gu et al., 2014). Additionally, CLF associated with EMF2 (EMF-PRC2 complex) is involved in the inhibition of 
LR formation, and the loss-of-function of either EMF2 or CLF results in greatly increased LR production along the primary roots. In the complex, CLF binds to and deposits the repressive mark $\mathrm{H} 3 \mathrm{~K} 27 \mathrm{me} 3$ to the chromatin of the auxin efflux carrier gene PIN FORMED 1 (PIN1); it downregulates auxin maxima in roots, thereby inhibiting the establishment of founder cells during LR initiation (Gu et al., 2014). PRC2 is involved in the repression of somatic embryo production in primary roots; the PRC2 mutants (swn clf, emf2 vrn2, and fie) display a certain proportion of "pkl-root" phenotype (Bouyer et al., 2011). PRC2 can prevent the unscheduled reprogramming of terminally differentiated root hair cells (Ikeuchi et al., 2015). A mature WT root hair is a unicellular structure that typically undergoes endoreduplication, which is a feature of fully differentiated cells with lost ability to re-enter the mitotic cycle (Breuer et al., 2010). The root hairs in swn clf and emf2 vrn2 first complete normal endoreduplication, but then they unexpectedly reactivate mitotic division to generate the multicellular structures and embryonic calli. The PRC2 target genes WIND3 and LEC2 contribute to reprogramming through their overexpression, mimicking the root hair defects of PRC2 mutants (Ikeuchi et al., 2015).

Specific transcriptional factors and enzymes associated with $\mathrm{PcG}$ proteins can regulate downstream gene expression and root development. Similar to animal GAGA-binding factors (Berger and Dubreucq, 2012), plant-specific BASIC PENTACYSTEINE/BARLEY B RECOMBINANT (BPC/BBR) proteins can bind to the GA-repeat promoter region in vitro (Meister et al., 2004; Wanke et al., 2011). Arabidopsis BPC proteins, including BPC1, BPC2, BPC4, and BPC6, can directly interact with the PRC2 subunit SWN, but not with CLF, VRN2, EMF2, and FIE; BPCs promote LR development though recruiting $\mathrm{PRC} 2$ to deposit $\mathrm{H} 3 \mathrm{~K} 27 \mathrm{me} 3$ repressive mark at the ABI4 locus (Mu et al., 2017). BPC6 can also recruit PcG protein LHP1 to polycomb-responsive DNA element-like GAGA motifs, and serve as a scaffold for the sequential attachment of PRC2 due to LHP1 interacting with PRC2 subunit VRN2 (Hecker et al., 2015). DNA topoisomerase TOPOISOMERASE1 $\alpha$ (TOP1 $\alpha$ ) influences PcG-mediated epigenetic regulation through reducing the nucleosome density in floral meristems (Liu et al., 2014), and it regulates root meristem activity through maintaining the genome integrity of stele stem cells and the undifferentiated state of CSCs (Zhang et al., 2016).

\section{HISTONE MONOUBIQUITINATION AND PRC1 COMPLEX IN ROOT DEVELOPMENT}

In Arabidopsis, the histone repressive mark $\mathrm{H} 2 \mathrm{Aub} 1$ is catalyzed by the PRC1 RING-finger proteins AtRING1a/b and AtBMIla/b/c (Bratzel et al., 2010; Li et al., 2017), which function throughout the life cycle and are implicated in regulating seed germination, vegetative maintenance, flowering time control, floral organ identity, and fertility [(Xu et al., 2005; Bratzel et al., 2010; Chen et al., 2010; Yang et al., 2013; Chen D. et al., 2016)]. PRC1 RING-finger proteins inhibit embryonic traits in primary root mainly through repressing the ectopic expression of seed maturation genes ABSCISIC ACID INSENSITIVE3 (ABI3),
FUSCA3 (FUS3), LEAFY COTYLEDON2 (LEC2), and LEAFY COTYLEDON1 (LEC1) (Bratzel et al., 2010; Chen et al., 2010). AtBMI1a/b/c can interact with B3 factors VP1/ABI3-LIKE (VAL) proteins, which are also required for preventing the vegetativeto-embryonic reversion in roots (Suzuki et al., 2007; Yang et al., 2013). Loss of VAL or AtBMI1 activity disrupts the incorporation of the repressive marks $\mathrm{H} 2 \mathrm{Aub} 1$ and $\mathrm{H} 3 \mathrm{~K} 27$ me 3 in seed maturation genes due to the strongly reduced levels of these two marks in vall val2 and atbmila atbmilb atbmilc mutants (Yang et al., 2013).

In addition to the signature B3 domain, VAL proteins harbor other conserved domains, such as the plant homeodomain (PHD) and cysteine and tryptophan residue-containing domain (CW), which usually act as histone code reader modules, and the ethylene-responsive element binding factor-associated amphiphilic repression (EAR) domain that functions as a repressive motif to recruit corepressors (Chen et al., 2018). In vitro assays showed that VAL1/2 may recognize dimethylated histone $\mathrm{H} 3$ lysine 4 (H3K4me2) and H3K4me3 through the CW domain or PHD domain and H3K27me3 through the PHD domain (Hoppmann et al., 2011; Chen et al., 2018). During the prevention of somatic embryogenesis, HIGH-LEVEL EXPRESSION OF SUGAR-INDUCIBLE GENE 2 (HSI2)/VAL1 binds to the two RY cis elements upstream of the AGL15 gene, recruits PRC2 subunit MSI1, and promotes the deposition of repressive mark $\mathrm{H} 3 \mathrm{~K} 27 \mathrm{me} 3$, thereby suppressing the seed maturation regulatory program (Chen et al., 2018). Additionally, HSI2/VAL1 can interact with HDA6 and the TRAP240 domain of MED13, which is a subunit of the conserved MEDIATOR (MED) complex linking transcription factors to the RNA polymerase II transcription machinery; HSI2/VAL1 recruits MED13 and HDA6 to suppress a subset of seed maturation genes in cotyledons (Chhun et al., 2016). However, HIGH-LEVEL EXPRESSION OF SUGAR-INDUCIBLE GENE2-LIKE1 (HSL1)/VAL2 but not HSI2/VAL1 can specifically interact with HDA19 through the CW domain; HSL1/VAL2 recruits HDA19 to directly repress the ectopic expression of seed maturation genes in seedlings (Zhou et al., 2013). Mutations in HDA19 or HSL1/VAL2 lead to the ectopic expression of seed maturation genes associated with the enrichment of gene activation marks ( $\mathrm{H} 3 \mathrm{ac}, \mathrm{H} 4 \mathrm{ac}$, and $\mathrm{H} 3 \mathrm{~K} 4 \mathrm{me} 3$ ) and reduction in levels of gene repression mark H3K27me3 in seedling (Zhou et al., 2013). The absence of HSL1/VAL2 and HDA19 leads to embryonic lethal (Zhou et al., 2013). Actually, HDA6 and HDA19 may redundantly contribute to the repression of embryonic traits after germination (Tanaka et al., 2008). These findings indicate that the existence of crosstalk among multiple chromatin modifiers for the coordinated control the vegetative-to-embryonic transition in the roots (Figure 1).

PRC1-related factors are also involved in other root developmental events. ALFIN1-like proteins (ALs) can recognize the active mark $\mathrm{H} 3 \mathrm{~K} 4 \mathrm{me} 3$ through the PHD-domain and interact with the RAWUL domain of PRC1 RING-finger proteins through the PAL domain (Molitor et al., 2014). Mutation in AL6 causes very short root hairs under phosphate starvation, which actually induces root hair elongation in WT (Chandrika et al., 2013a,b). LHP1 is considered as a Pc equivalent of PRC1 for recognizing the $\mathrm{H} 3 \mathrm{~K} 27 \mathrm{me} 3$ mark (Gaudin et al., 2001), 


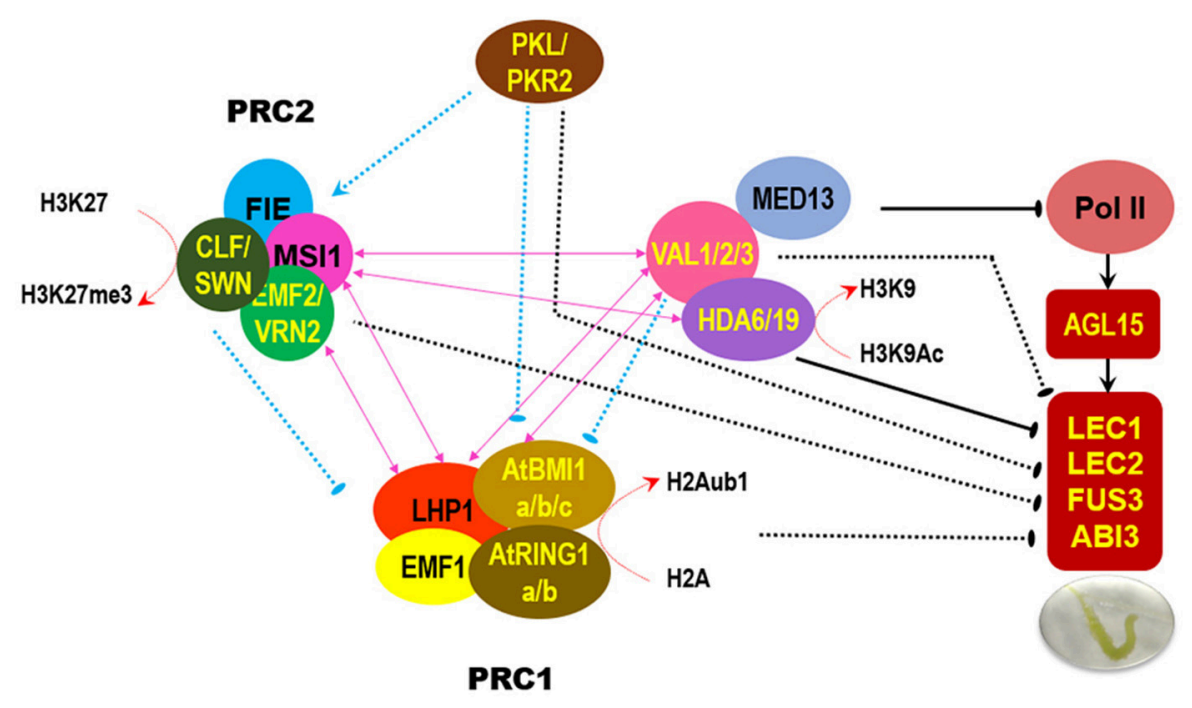

FIGURE 1 | Regulatory relationship among distinct chromatin modifiers for repressing development of embryonic traits in the root. The schematic summary is mainly based on the published results (Derkacheva et al., 2013; Zhou et al., 2013; Hecker et al., 2015; Mehdi et al., 2016; Yuan et al., 2016). Pink double-headed arrow indicates direct protein-protein interaction. "T" bar indicates repressive effect, arrow indicates promotive effect; solid line means direct target gene, dash line means uncertain downstream target.

however, it can also interact with PRC2 subunits MSI1, EMF2, and VRN2 (Derkacheva et al., 2013; Hecker et al., 2015); thus, LHP1 may act as a bridge between PRC1 and PRC2 (Feng and Lu, 2017). The lhpl mutant phenotype is closer to PRC1 mutant emf1 and PRC2 mutants clf and emf2 than to PRC1 mutants atring $1 a$ atring $1 b$ and atbmila atbmi1b, indicating LHP1 may exert specific function independent of PRC1 RING finger proteins. For instance, unlike PRC1 RING finger proteins repressing embryonic traits in root, LHP1 interacts with SCR to suppress premature middle cortex formation which is derived from extra longitudinal asymmetric cell divisions in the ground tissue (Cui and Benfey, 2009). Furthermore, the premature middle cortex phenotype in $\operatorname{lhp} 1$ or $s c r$ mutants similar to GA signaling mutants can be suppressed by phytohormone gibberellin (GA) but is enhanced by GA biosynthesis inhibitor paclobutrazol (Paquette and Benfey, 2005; Cui and Benfey, 2009), indicating the interplay between phytohormone signaling and chromatin-based regulation in regulating middle cortex formation.

\section{CHROMATIN REMODELING IN ROOT DEVELOPMENT}

Chromatin-remodeling ATPases in eukaryotes consists of four major subfamilies (SWI/SNF, ISWI, CHD, and INO80/SWR1) and many additional types (Clapier and Cairns, 2009; Han et al., 2015). Thereinto, SWI2/SNF2 subfamily contains four members: BRAHMA (BRM), SPLAYED (SYD), CHR12, and CHR23 (Flaus et al., 2006). In Arabidopsis, CHD3 chromatin remodeler PICKLE (PKL) plays the essential roles in root development. It inhibits the vegetative-to-embryonic revision by repressing the expression of seed maturation genes in postembryonic roots (Ogas et al., 1999). Mutation of PKL causes a low penetrance of " $\mathrm{pkl}$ root" phenotype, which displays a swollen and green primary root with embryonic traits and accumulation of seed storage reserves (Ogas et al., 1999; Aichinger et al., 2009), reminiscent of the phenotype of some PcG mutants, such as atringla atring1b, atbmila atbmi1b, swn clf, and emf2 vrn2. ChIP experiment showed that PKL can directly target PcG genes SWN and EMF2 in roots; lack of both PKL and its paralog PKR2 can result in reduced $\mathrm{H} 3 \mathrm{~K} 27 \mathrm{me} 3$ levels and increased expression of a set of PcG target genes in roots, similar to PcG mutant (Aichinger et al., 2009). PKL is involved in most GA-promoted vegetative growth and phase transitions; GA deficiency can dramatically increase the "pkl root" phenotype in pkl mutant (Park et al., 2017). PKL is required for root meristem maintenance, and $p k l$ mutant displays shorter root and decreased root meristem activity (Aichinger et al., 2011). PcG protein CLF and PKL antagonistically determine root stem cell activity; depletion of CLF leads to increased root meristematic activity (Aichinger et al., 2011). PKL/SSL2 represses auxin-mediated LR initiation through counteracting auxin signaling repressor SLR, which suppresses downstream activators ARF7 and ARF19. Similar to TSA treatment, $p k l$ mutation restores LR formation of the gainof-function allele $s l r-1$, as does (Fukaki et al., 2006). In rice, PKL/CHD3 homolog CHR729 regulates multiple developmental events including root growth via the gibberellin pathway; the phenotype of the chr729 mutant with reduced bioactive GA3 can be partially rescued by exogenous GA3 (Ma et al., 2015). CHR729 can respectively bind to $\mathrm{H} 3 \mathrm{~K} 4 \mathrm{me} 2$ and $\mathrm{H} 3 \mathrm{~K} 27 \mathrm{me} 3$ through its chromodomain and PHD domain; disruption of CHR729 gives rise to a global decrease of $\mathrm{H} 3 \mathrm{~K} 27 \mathrm{me} 3$ and $\mathrm{H} 3 \mathrm{~K} 4 \mathrm{me} 3$, but not $\mathrm{H} 3 \mathrm{~K} 4 \mathrm{me} 2$ and $\mathrm{H} 3 \mathrm{~K} 4 \mathrm{me} 1$ (Hu et al., 2012). These indicate that 
CHR729 acts as a bifunctional remodeler to read and interpret histone marks ( $\mathrm{Hu}$ et al., 2012). Another rice $\mathrm{CHD}$ protein CROWN ROOTLESS6 (CRL6) is required for the development of shoot-born crown roots via the auxin signaling pathway (Wang et al., 2016).

SWI/SNF remodeler BRM regulates primary root elongation in an ABA-dependent manner, and it can bind to the $A B I 5$ locus (Han et al., 2012). The brm mutant exhibits ABA hypersensitivity and increased drought tolerance, mimicking the ABI5 overexpression phenotype. This finding indicates that BRM mediates the balance between growth and stress responses through the ABA signaling pathway. Additionally, BRM maintains root SCN dependent on the PLETHORA (PLT) pathway by directly targeting the chromatin of several PIN genes (PIN1-PIN4, and PIN7) and affecting auxin distribution. PLT2 overexpression can partially rescue a $\mathrm{brm}$ SCN defect (Yang et al., 2015). Furthermore, BRM interacts with the SUMO ligase AtMMS21, which can stabilize BRM protein by SUMOylation in roots. AtMMS21 mutation results in decreased BRM protein level (Zhang et al., 2017). The SWI/SNF complex subunit BAF60 promotes root growth and RAM size through controlling phytohormone cytokinin (CK) production and cell cycle progression via repressing the active histone mark deposition and chromatin loop formation on the key CK biosynthesis genes IPT3 and IPT7 and cell cycle inhibitor KRP7 (Jegu et al., 2015). CHR12/MINUSCULE1 (MINU1) and CHR23/MINU2 are required for root development and RAM maintenance. The chr12 or chr23 single mutants display WTlike phenotype, but knockout of both in chr12 chr23 strong double mutant causes embryonic lethality without root and shoot meristems initiation. In the weak double mutant, dramatically defective RAM including hardly identified QC and irregular columella cell layer results from aberrantly oriented cell division and impaired division rate (Sang et al., 2012). Furthermore, CHR23 can directly bind to the WOX 5 promoter and repress its expression. By contrast, overexpression of CHR23 reduces root growth due to reduced cell elongation and increases phenotypic variation in accordance with increased expression variability of subsets of environmental stress-related genes among genetically identical individuals (Folta et al., 2014). Therefore, CHR23mediated chromatin remodeling might provide a buffer system to ensure growth robustness against environmentally-induced phenotypic and transcriptional variation (Folta et al., 2014).

\section{CONCLUSIONS AND PERSPECTIVES}

The performance of the root system is dependent on the formation of primary, lateral and adventitious roots. Chromatin modification mainly consists of DNA methylation, histone modification and chromatin remodeling. Although DNA methylation is involved in multiple developmental phases, its role in root development is a mystery and needs systematical investigation. Histone modification and chromatin remodeling has been demonstrated to participate in diverse aspects of root system development, such as root elongation, LR initiation, stress response, cell patterning, stem cell maintenance, cell fate determination, and cell proliferation and differentiation, but most of the related reports only focus on the model plants
Arabidopsis and rice. Comparing and elucidating chromatinbased regulatory mechanisms of different root types (like epiphytic root and storage root) in distinct plants will deepen our understanding of root function and phylogenesis. Root developmental progresses is closely associated with stem cell fate transition during RAM differentiation, where the dynamic change and action mechanism of epigenetic marks in specific cell lineage need to be addressed.

Chromatin modifications usually have global yet uneven distribution throughout the plant life cycle, and depletion of each modification type often causes pleiotropic phenotypes in addition to abnormal root development, such as clf mutant with curly leaf, early flowering and homeotic conversion of floral organ (Goodrich et al., 1997), and atring1a atring1b double mutant with ectopic meristem, twisted blade, late flowering, overproliferated floral organ, and poor fertility ( $\mathrm{Xu}$ and Shen, 2008; Chen et al., 2010; Chen D. et al., 2016). Such modifications may form different combinations allowing for accurate and fine regulation of developmental processes. (1) Chromatin modifiers with antagonistic functions precisely maintain the homeostasis of chromatin modifications to ensure normal growth and development of plants. (2) Different types of chromatin modifiers may constitute a single multiprotein complex or act together to exert complicated functions. CHD3 family members in animals belong to the NuRD (nucleosome remodeling and deacetylase) complex that participates in transcriptional repression through coupling chromatin remodeling and deacetylation (Bouazoune and Brehm, 2006). Consistently, Arabidopsis CHD3 remodeler PKL and histone acetylation are involved in repressing auxin-mediated LR initiation (Fukaki et al., 2006). (3) Distinct complex variants form dependent on the specific developmental phase. PRC2 complex variants EMF-PRC2, VRN-PRC2, and FIS-PRC2 function in vegetative maintenance, vernalization, and endosperm development, respectively (Bemer and Grossniklaus, 2012). (4) Alteration of work mode occurs in specific developmental context. PRC1-mediated H2Aub1 initiates the repression of seed maturation genes and subsequent recruit PRC2 complex to maintain repression through introducing H3K27me3 marks, different from the classic hierarchical model in animal PcGmediated repression, where $\mathrm{H} 3 \mathrm{~K} 27 \mathrm{me} 3$ precedes $\mathrm{H} 2 \mathrm{Aub} 1$ (Yang et al., 2013). A chromatin modifier may harbor dual roles. For instance, rice chromatin remodeler OsCHR729 may recognize histone methylation (Hu et al., 2012). These regulatory modes in different developmental events provide essential references for chromatin-based mechanism underlying root development.

To date, only a small number of chromatin modifiers displaying obvious phenotype in single mutants and to a less extent in double mutants have been functionally characterized in the roots, whereas lack of investigations on most chromatin modifiers might be difficult in phenotype analysis due to existence of multiple redundant genes. The newly-developed CRISPR (clustered regularly interspaced short palindromic)/Cas (CRISPR-associated) system provides an extremely powerful and labor-saving tool for targeted gene editing. This tool can be used to target several genes simultaneously for fast and efficient generation of high-order mutants (Cong et al., 2013; 
Shan et al., 2013). Additionally, the fast-growing multiple omics technologies (transcriptomics, proteomics, and epigenomics) associated with conventional experiments (ChIP, Pull-down, and affinity purification) can be used for high-throughput identification of the target genes and partners of chromatin modifiers to elucidate their functions in root development. Gene transformation is not established in many plants with different root types, thereby limiting the application of the CRISPR/Cas system and production of mutants in these plants. Hence, exploitation of novel inhibitors is preferable to chromatin modifiers for mutant mimicking and human epigenetic disease therapy.

\section{REFERENCES}

Aichinger, E., Kornet, N., Friedrich, T., and Laux, T. (2012). Plant stem cell niches. Аnnu. Rev. Plant. Biol. 63, 615-636. doi: 10.1146/annurev-arplant-042811-105555

Aichinger, E., Villar, C. B., Di Mambro, R., Sabatini, S., and Köhler, C. (2011). The CHD3 chromatin remodeler PICKLE and polycomb group proteins antagonistically regulate meristem activity in the Arabidopsis root. Plant Cell 23, 1047-1060. doi: 10.1105/tpc.111.083352

Aichinger, E., Villar, C. B., Farrona, S., Reyes, J. C., Hennig, L., and Kohler, C. (2009). CHD3 proteins and polycomb group proteins antagonistically determine cell identity in Arabidopsis. PLoS Genet. 5:e1000605. doi: 10.1371/journal.pgen.1000605

Bemer, M., and Grossniklaus, U. (2012). Dynamic regulation of Polycomb group activity during plant development. Curr. Opin. Plant Biol. 15, 523-529. doi: 10.1016/j.pbi.2012.09.006

Berger, N., and Dubreucq, B. (2012). Evolution goes GAGA: GAGA binding proteins across kingdoms. Biochim. Biophys. Acta 1819, 863-868. doi: 10.1016/j.bbagrm.2012.02.022

Berr, A., McCallum, E. J., Menard, R., Meyer, D., Fuchs, J., Dong, A., et al. (2010). Arabidopsis SET DOMAIN GROUP2 is required for H3K4 trimethylation and is crucial for both sporophyte and gametophyte development. Plant Cell 22, 3232-3248. doi: 10.1105/tpc.110.079962

Bouazoune, K., and Brehm, A. (2006). ATP-dependent chromatin remodeling complexes in Drosophila. Chromosome Res. 14, 433-449. doi: 10.1007/s10577-006-1067-0

Bouyer, D., Roudier, F., Heese, M., Andersen, E. D., Gey, D., Nowack, M. K., et al. (2011). Polycomb repressive complex 2 controls the embryo-to-seedling phase transition. PLoS Genet. 7:e1002014. doi: 10.1371/journal.pgen.1002014

Bratzel, F., Lopez-Torrejon, G., Koch, M., Del Pozo, J. C., and Calonje, M. (2010). Keeping cell identity in Arabidopsis requires PRC1 RING-finger homologs that catalyze H2A monoubiquitination. Curr. Biol. 20, 1853-1859. doi: 10.1016/j.cub.2010.09.046

Breuer, C., Ishida, T., and Sugimoto, K. (2010). Developmental control of endocycles and cell growth in plants. Curr. Opin. Plant Biol. 13, 654-660. doi: 10.1016/j.pbi.2010.10.006

Caro, E., Castellano, M. M., and Gutierrez, C. (2007). A chromatin link that couples cell division to root epidermis patterning in Arabidopsis. Nature 447, 213-217. doi: $10.1038 /$ nature 05763

Casimiro, I., Marchant, A., Bhalerao, R. P., Beeckman, T., Dhooge, S., Swarup, R., et al. (2001). Auxin transport promotes Arabidopsis lateral root initiation. Plant Cell 13, 843-852. doi: 10.1105/tpc.13.4.843

Chandrika, N. N., Sundaravelpandian, K., and Schmidt, W. (2013a). A PHD in histone language: on the role of histone methylation in plant responses to phosphate deficiency. Plant Signal. Behav. 8:e24381. doi: 10.4161/psb.24381

Chandrika, N. N., Sundaravelpandian, K., Yu, S. M., and Schmidt, W. (2013b). ALFIN-LIKE 6 is involved in root hair elongation during phosphate deficiency in Arabidopsis. New Phytol. 198, 709-720. doi: 10.1111/nph.12194

Chen, D., Molitor, A., Liu, C., and Shen, W. H. (2010). The Arabidopsis PRC1like ring-finger proteins are necessary for repression of embryonic traits during vegetative growth. Cell Res. 20, 1332-1344. doi: 10.1038/cr.2010.151

\section{AUTHOR CONTRIBUTIONS}

D-HC and $\mathrm{YH}$ wrote the manuscript. CJ collected the raw materials. J-PS provided important suggestions.

\section{FUNDING}

This work was support by grants from National Key R\&D Program of China (2017YFC1702201), National Natural Science Foundation of China (31870310), and Scientific R\&D Foundation for Talent Start-up Project of Zhejiang A\&F University (102/2034020128).

Chen, D., Molitor, A. M., Xu, L., and Shen, W. H. (2016). Arabidopsis PRC1 core component AtRING1 regulates stem cell-determining carpel development mainly through repression of class I KNOX genes. BMC Biol. 14:112. doi: 10.1186/s12915-016-0336-4

Chen, D. H., Huang, Y., Ruan, Y., and Shen, W. H. (2016). The evolutionary landscape of PRC1 core components in green lineage. Planta 243, 825-846. doi: 10.1007/s00425-015-2451-9

Chen, N., Veerappan, V., Abdelmageed, H., Kang, M., and Allen, R. D. (2018). HSI2/VAL1 silences AGL15 to regulate the developmental transition from seed maturation to vegetative growth in arabidopsis. Plant Cell 30, 600-619. doi: $10.1105 /$ tpc. 17.00655

Chen, W. Q., Li, D. X., Zhao, F., Xu, Z. H., and Bai, S. N. (2016). One additional histone deacetylase and 2 histone acetyltransferases are involved in cellular patterning of Arabidopsis root epidermis. Plant Signal. Behav. 11:e1131373. doi: 10.1080/15592324.2015.1131373

Chhun, T., Chong, S. Y., Park, B. S., Wong, E. C., Yin, J. L., Kim, M., et al. (2016). HSI2 Repressor recruits MED13 and HDA6 to down-regulate seed maturation gene expression directly during arabidopsis early seedling growth. Plant Cell Physiol. 57, 1689-1706. doi: 10.1093/pcp/pcw095

Chung, P. J., Kim, Y. S., Jeong, J. S., Park, S. H., Nahm, B. H., and Kim, J. K. (2009). The histone deacetylase OsHDAC1 epigenetically regulates the OsNAC6 gene that controls seedling root growth in rice. Plant J. 59, 764-776. doi: 10.1111/j.1365-313X.2009.03908.x

Clapier, C. R., and Cairns, B. R. (2009). The biology of chromatin remodeling complexes. Annu. Rev. Biochem. 78, 273-304. doi: 10.1146/annurev.biochem.77.062706.153223

Cong, L., Ran, F. A., Cox, D., Lin, S., Barretto, R., Habib, N., et al. (2013). Multiplex genome engineering using CRISPR/Cas systems. Science 339, 819-823. doi: $10.1126 /$ science. 1231143

Cui, H., and Benfey, P. N. (2009). Interplay between scarecrow, GA and like heterochromatin protein 1 in ground tissue patterning in the Arabidopsis root. Plant J. 58, 1016-1027. doi: 10.1111/j.1365-313X.2009.0 3839.x

de Lucas, M., Pu, L., Turco, G., Gaudinier, A., Morao, A. K., Harashima, H., et al. (2016). Transcriptional regulation of arabidopsis polycomb repressive complex 2 coordinates cell-type proliferation and differentiation. Plant Cell 28, 2616-2631. doi: 10.1105/tpc.15. 00744

De Smet, I., Vassileva, V., De Rybel, B., Levesque, M. P., Grunewald, W., Van Damme, D., et al. (2008). Receptor-like kinase ACR4 restricts formative cell divisions in the Arabidopsis root. Science 322, 594-597. doi: $10.1126 /$ science. 1160158

Derkacheva, M., Steinbach, Y., Wildhaber, T., Mozgova, I., Mahrez, W., Nanni, P., et al. (2013). Arabidopsis MSI1 connects LHP1 to PRC2 complexes. EMBO J. 32, 2073-2085. doi: 10.1038/emboj.2013.145

Dolan, L., Janmaat, K., Willemsen, V., Linstead, P., Poethig, S., Roberts, K., et al. (1993). Cellular organisation of the Arabidopsis thaliana root. Development 119, 71-84.

Drisch, R. C., and Stahl, Y. (2015). Function and regulation of transcription factors involved in root apical meristem and stem cell maintenance. Front. Plant Sci. 6:505. doi: 10.3389/fpls.2015.00505 
Dubrovsky, J. G., Rost, T. L., Colon-Carmona, A., and Doerner, P. (2001). Early primordium morphogenesis during lateral root initiation in Arabidopsis thaliana. Planta 214, 30-36. doi: 10.1007/s004250100598

Eberharter, A., and Becker, P. B. (2002). Histone acetylation: a switch between repressive and permissive chromatin. Second in review series on chromatin dynamics. EMBO Rep. 3, 224-229. doi: 10.1093/embo-reports/kvf053

Feng, J., and Lu, J. (2017). LHP1 could act as an activator and a repressor of transcription in plants. Front. Plant Sci. 8:2041. doi: 10.3389/fpls.2017.02041

Flaus, A., Martin, D. M., Barton, G. J., and Owen-Hughes, T. (2006). Identification of multiple distinct Snf2 subfamilies with conserved structural motifs. Nucleic Acids Res. 34, 2887-2905. doi: 10.1093/nar/gkl295

Folta, A., Severing, E. I., Krauskopf, J., van de Geest, H., Verver, J., Nap, J. P., et al. (2014). Over-expression of arabidopsis AtCHR23 chromatin remodeling ATPase results in increased variability of growth and gene expression. BMC Plant Biol. 14:76. doi: 10.1186/1471-2229-14-76

Forderer, A., Zhou, Y., and Turck, F. (2016). The age of multiplexity: recruitment and interactions of Polycomb complexes in plants. Curr. Opin. Plant Biol. 29, 169-178. doi: 10.1016/j.pbi.2015.11.010

Fukaki, H., Taniguchi, N., and Tasaka, M. (2006). PICKLE is required for solitary-root/IAA14-mediated repression of ARF7 and ARF19 activity during Arabidopsis lateral root initiation. Plant J. 48, 380-389. doi: 10.1111/j.1365-313X.2006.02882.X

Gaudin, V., Libault, M., Pouteau, S., Juul, T., Zhao, G., Lefebvre, D., et al. (2001). Mutations in LIKE HETEROCHROMATIN PROTEIN 1 affect flowering time and plant architecture in Arabidopsis. Development 128, 4847-4858.

Gilroy, S., and Jones, D. L. (2000). Through form to function: root hair development and nutrient uptake. Trends Plant Sci. 5, 56-60. doi: 10.1016/S1360-1385(99)01551-4

Goodrich, J., Puangsomlee, P., Martin, M., Long, D., Meyerowitz, E. M., and Coupland, G. (1997). A Polycomb-group gene regulates homeotic gene expression in Arabidopsis. Nature 386, 44-51. doi: 10.1038/386044a0

$\mathrm{Gu}, \mathrm{X} ., \mathrm{Xu}, \mathrm{T}$. , and He, Y. (2014). A histone H3 lysine-27 methyltransferase complex represses lateral root formation in Arabidopsis thaliana. Mol. Plant 7, 977-988. doi: 10.1093/mp/ssu035

Hakimi, M. A., Bochar, D. A., Chenoweth, J., Lane, W. S., Mandel, G., and Shiekhattar, R. (2002). A core-BRAF35 complex containing histone deacetylase mediates repression of neuronal-specific genes. Proc. Natl. Acad. Sci. U.S.A. 99, 7420-7425. doi: 10.1073/pnas.112008599

Han, S. K., Sang, Y., Rodrigues, A., Biol, F., Wu, M. F., Rodriguez, P. L., et al. (2012). The SWI2/SNF2 chromatin remodeling ATPase brahma represses abscisic acid responses in the absence of the stress stimulus in Arabidopsis. Plant Cell 24, 4892-4906. doi: 10.1105/tpc.112.105114

Han, S. K., Wu, M. F., Cui, S., and Wagner, D. (2015). Roles and activities of chromatin remodeling ATPases in plants. Plant J. 83, 62-77. doi: $10.1111 /$ tpj. 12877

Hecker, A., Brand, L. H., Peter, S., Simoncello, N., Kilian, J., Harter, K., et al. (2015). The Arabidopsis GAGA-binding factor basic pentacysteine6 Recruits the polycomb-repressive complex1 component like heterochromatin protein 1 to GAGA DNA motifs. Plant Physiol. 168, 1013-1024. doi: 10.1104/pp.15.00409

Hollender, C., and Liu, Z. (2008). Histone deacetylase genes in Arabidopsis development. J. Integr. Plant Biol. 50, 875-885. doi: 10.1111/j.1744-7909.2008.00704.x

Hoppmann, V., Thorstensen, T., Kristiansen, P. E., Veiseth, S. V., Rahman, M. A., Finne, K., et al. (2011). The CW domain, a new histone recognition module in chromatin proteins. EMBO J. 30, 1939-1952. doi: 10.1038/emboj.2011.108

Hu, Y., Liu, D., Zhong, X., Zhang, C., Zhang, Q., and Zhou, D. X. (2012). CHD3 protein recognizes and regulates methylated histone $\mathrm{H} 3$ lysines 4 and 27 over a subset of targets in the rice genome. Proc Natl Acad Sci U.S.A. 109, 5773-5778. doi: 10.1073/pnas.1203148109

Hu, Y., Zhu, N., Wang, X., Yi, Q., Zhu, D., Lai, Y., et al. (2013). Analysis of rice Snf2 family proteins and their potential roles in epigenetic regulation. Plant Physiol. Biochem. 70, 33-42. doi: 10.1016/j.plaphy.2013.05.001

Huang, H., Sabari, B. R., Garcia, B. A., Allis, C. D., and Zhao, Y. (2014). SnapShot: histone modifications. Cell 159, 458.e1-458.e1. doi: 10.1016/j.cell.2014.09.037

Humphrey, G. W., Wang, Y., Russanova, V. R., Hirai, T., Qin, J., Nakatani, Y., et al. (2001). Stable histone deacetylase complexes distinguished by the presence of SANT domain proteins CoREST/kiaa0071 and Mta-L1. J. Biol. Chem. 276, 6817-6824. doi: 10.1074/jbc.M007372200
Ikeuchi, M., Iwase, A., Rymen, B., Harashima, H., Shibata, M., Ohnuma, M., et al. (2015). PRC2 represses dedifferentiation of mature somatic cells in Arabidopsis. Nat. Plants. 1:15089. doi: 10.1038/nplants.2015.89

Ivanov, V. B., and Dubrovsky, J. G. (2013). Longitudinal zonation pattern in plant roots: conflicts and solutions. Trends Plant Sci. 18, 237-243. doi: 10.1016/j.tplants.2012.10.002

Jang, I. C., Pahk, Y. M., Song, S. I., Kwon, H. J., Nahm, B. H., and Kim, J. K. (2003). Structure and expression of the rice class-I type histone deacetylase genes OsHDAC1-3: OsHDAC1 overexpression in transgenic plants leads to increased growth rate and altered architecture. Plant J. 33, 531-541. doi: 10.1046/j.1365-313X.2003.01650.x

Jegu, T., Domenichini, S., Blein, T., Ariel, F., Christ, A., Kim, S. K., et al. (2015). A SWI/SNF chromatin remodelling protein controls cytokinin production through the regulation of chromatin architecture. PLOS ONE 10:e0138276. doi: 10.1371/journal.pone.0138276

Jiang, D., Yang, W., He, Y., and Amasino, R. M. (2007). Arabidopsis relatives of the human lysine-specific Demethylase1 repress the expression of FWA and flowering locus C and thus promote the floral transition. Plant Cell 19, 2975-2987. doi: 10.1105/tpc.107.052373

Jullien, P. E., Susaki, D., Yelagandula, R., Higashiyama, T., and Berger, F. (2012). DNA methylation dynamics during sexual reproduction in Arabidopsis thaliana. Curr. Biol. 22, 1825-1830. doi: 10.1016/j.cub.2012.07.061

Kawakatsu, T., Stuart, T., Valdes, M., Breakfield, N., Schmitz, R. J., Nery, J. R., et al. (2016). Unique cell-type-specific patterns of DNA methylation in the root meristem. Nat. Plants 2:16058. doi: 10.1038/nplants.2016.58

Knizewski, L., Ginalski, K., and Jerzmanowski, A. (2008). Snf2 proteins in plants: gene silencing and beyond. Trends Plant Sci. 13, 557-565. doi: $10.1016 /$ j.tplants.2008.08.004

Kohler, C., and Hennig, L. (2010). Regulation of cell identity by plant Polycomb and trithorax group proteins. Curr. Opin. Genet. Dev. 20, 541-547. doi: 10.1016/j.gde.2010.04.015

Kornet, N., and Scheres, B. (2009). Members of the GCN5 histone acetyltransferase complex regulate PLETHORA-mediated root stem cell niche maintenance and transit amplifying cell proliferation in Arabidopsis. Plant Cell 21, 1070-1079. doi: 10.1105/tpc.108.065300

Krichevsky, A., Zaltsman, A., Kozlovsky, S. V., Tian, G. W., and Citovsky, V. (2009). Regulation of root elongation by histone acetylation in Arabidopsis. J. Mol. Biol. 385, 45-50. doi: 10.1016/j.jmb.2008.09.040

Kumpf, R., Thorstensen, T., Rahman, M. A., Heyman, J., Nenseth, H. Z., Lammens, T., et al. (2014). The ASH1-RELATED3 SET-domain protein controls cell division competence of the meristem and the quiescent center of the Arabidopsis primary root. Plant Physiol. 166, 632-643. doi: $10.1104 /$ pp.114.244798

Lafos, M., Kroll, P., Hohenstatt, M. L., Thorpe, F. L., Clarenz, O., and Schubert, D. (2011). Dynamic regulation of H3K27 trimethylation during Arabidopsis differentiation. PLoS Genet. 7:e1002040. doi: 10.1371/journal.pgen.1002040

Law, J. A., and Jacobsen, S. E. (2010). Establishing, maintaining and modifying DNA methylation patterns in plants and animals. Nat. Rev. Genet. 11, 204-220. doi: $10.1038 / \operatorname{nrg} 2719$

Lawrence, M., Daujat, S., and Schneider, R. (2016). Lateral Thinking: how histone modifications regulate gene expression. Trends Genet. 32, 42-56. doi: 10.1016/j.tig.2015.10.007

Li, B., Carey, M., and Workman, J. L. (2007). The role of chromatin during transcription. Cell 128, 707-719. doi: 10.1016/j.cell.2007.01.015

Li, D. X., Chen, W. Q., Xu, Z. H., and Bai, S. N. (2015). Histone deacetylase6defective mutants show increased expression and acetylation of enhancer of triptychon and CAPRICE1 and GLABRA2 with small but significant effects on root epidermis cellular pattern. Plant Physiol. 168, 1448-1458. doi: 10.1104/pp.15.00821

Li, H., Torres-Garcia, J., Latrasse, D., Benhamed, M., Schilderink, S., Zhou, W., et al. (2017). Plant-specific histone deacetylases HDT1/2 regulate GIBBERELLIN 2-OXIDASE2 expression to control arabidopsis root meristem cell number. Plant Cell 29, 2183-2196. doi: 10.1105/tpc.17. 00366

Li, H., Yan, S., Zhao, L., Tan, J., Zhang, Q., Gao, F., et al. (2014). Histone acetylation associated up-regulation of the cell wall related genes is involved in salt stress induced maize root swelling. BMC Plant Biol. 14:105. doi: $10.1186 / 1471-2229-14-105$ 
Li, J., Wang, Z., Hu, Y., Cao, Y., and Ma, L. (2017). Polycomb group proteins RING1A and RING1B regulate the vegetative phase transition in arabidopsis. Front. Plant Sci. 8:867. doi: 10.3389/fpls.2017.00867

Liu, C., Li, L. C., Chen, W. Q., Chen, X., Xu, Z. H., and Bai, S. N. (2013). HDA18 affects cell fate in Arabidopsis root epidermis via histone acetylation at four kinase genes. Plant Cell 25, 257-269. doi: 10.1105/tpc.112.107045

Liu, X., Gao, L., Dinh, T. T., Shi, T., Li, D., Wang, R., et al. (2014). DNA topoisomerase I affects polycomb group protein-mediated epigenetic regulation and plant development by altering nucleosome distribution in Arabidopsis. Plant Cell 26, 2803-2817. doi: 10.1105/tpc.114.124941

Luger, K., Mader, A. W., Richmond, R. K., Sargent, D. F., and Richmond, T. J. (1997). Crystal structure of the nucleosome core particle at 2.8 A resolution. Nature 389, 251-260. doi: 10.1038/38444

Ma, X., Ma, J., Zhai, H., Xin, P., Chu, J., Qiao, Y., et al. (2015). CHR729 Is a CHD3 protein that controls seedling development in rice. PLOS ONE 10:e0138934. doi: 10.1371/journal.pone.0138934

Ma, X., Zhang, C., Zhang, B., Yang, C., and Li, S. (2016). Identification of genes regulated by histone acetylation during root development in Populus trichocarpa. BMC Genomics 17:96. doi: 10.1186/s12864-016-2407-x

Malamy, J. E., and Benfey, P. N. (1997). Organization and cell differentiation in lateral roots of Arabidopsis thaliana. Development 124, 33-44.

Manzano, C., Ramirez-Parra, E., Casimiro, I., Otero, S., Desvoyes, B., De Rybel, B., et al. (2012). Auxin and epigenetic regulation of SKP2B, an F-box that represses lateral root formation. Plant Physiol. 160, 749-762. doi: 10.1104/pp.112.198341

Mehdi, S., Derkacheva, M., Ramstrom, M., Kralemann, L., Bergquist, J., and Hennig, L. (2016). The WD40 domain protein MSI1 functions in a histone deacetylase complex to fine-tune abscisic acid signaling. Plant Cell 28, 42-54. doi: $10.1105 /$ tpc. 15.00763

Meister, R. J., Williams, L. A., Monfared, M. M., Gallagher, T. L., Kraft, E. A., Nelson, C. G., et al. (2004). Definition and interactions of a positive regulatory element of the Arabidopsis INNER NO OUTER promoter. Plant J. 37, 426-438. doi: 10.1046/j.1365-313X.2003.01971.x

Molitor, A. M., Bu, Z., Yu, Y., and Shen, W. H. (2014). Arabidopsis AL PHDPRC1 complexes promote seed germination through H3K4me3-to-H3K27me3 chromatin state switch in repression of seed developmental genes. PLoS Genet. 10:e1004091. doi: 10.1371/journal.pgen.1004091

Mu, Y., Zou, M., Sun, X., He, B., Xu, X., Liu, Y., et al. (2017). Basic pentacysteine proteins repress abscisic acid INSENSITIVE4 expression via direct recruitment of the polycomb-repressive complex 2 in arabidopsis root development. Plant Cell Physiol. 58, 607-621. doi: 10.1093/pcp/pcx006

Napsucialy-Mendivil, S., Alvarez-Venegas, R., Shishkova, S., and Dubrovsky, J. G. (2014). Arabidopsis homolog of trithorax1 (ATX1) is required for cell production, patterning, and morphogenesis in root development. J. Exp. Bot. 65, 6373-6384. doi: 10.1093/jxb/eru355

Narlikar, G. J., Fan, H. Y., and Kingston, R. E. (2002). Cooperation between complexes that regulate chromatin structure and transcription. Cell 108, 475-487. doi: 10.1016/S0092-8674(02)0 0654-2

Narlikar, G. J., Sundaramoorthy, R., and Owen-Hughes, T. (2013). Mechanisms and functions of ATP-dependent chromatin-remodeling enzymes. Cell 154, 490-503. doi: 10.1016/j.cell.2013.07.011

Ng, D. W., Wang, T., Chandrasekharan, M. B., Aramayo, R., Kertbundit, S., and Hall, T. C. (2007). Plant SET domain-containing proteins: structure, function and regulation. Biochim. Biophys. Acta 1769, 316-329. doi: 10.1016/j.bbaexp.2007.04.003

Nguyen, H. N., Kim, J. H., Jeong, C. Y., Hong, S. W., and Lee, H. (2013). Inhibition of histone deacetylation alters Arabidopsis root growth in response to auxin via PIN1 degradation. Plant Cell Rep. 32, 1625-1636. doi: 10.1007/s00299-013-1474-6

Ogas, J., Kaufmann, S., Henderson, J., and Somerville, C. (1999). PICKLE is a CHD3 chromatin-remodeling factor that regulates the transition from embryonic to vegetative development in Arabidopsis. Proc Natl Acad Sci U.S.A. 96, 13839-13844. doi: 10.1073/pnas.96.24.13839

Pandey, R., Muller, A., Napoli, C. A., Selinger, D. A., Pikaard, C. S., Richards, E. J., et al. (2002). Analysis of histone acetyltransferase and histone deacetylase families of Arabidopsis thaliana suggests functional diversification of chromatin modification among multicellular eukaryotes. Nucleic Acids Res. 30, 5036-5055. doi: 10.1093/nar/gkf660
Paquette, A. J., and Benfey, P. N. (2005). Maturation of the ground tissue of the root is regulated by gibberellin and SCARECROW and requires SHORT-ROOT. Plant Physiol. 138, 636-640. doi: 10.1104/pp.104.058362

Park, J., Oh, D. H., Dassanayake, M., Nguyen, K. T., Ogas, J., Choi, G., et al. (2017). Gibberellin signaling requires chromatin remodeler PICKLE to promote vegetative growth and phase transitions. Plant Physiol. 173, 1463-1474. doi: 10.1104/pp.16.01471

Peret, B., De Rybel, B., Casimiro, I., Benkova, E., Swarup, R., Laplaze, L., et al. (2009). Arabidopsis lateral root development: an emerging story. Trends Plant Sci. 14, 399-408. doi: 10.1016/j.tplants.2009.05.002

Pi, L., Aichinger, E., van der Graaff, E., Llavata-Peris, C. I., Weijers, D., Hennig, L., et al. (2015). Organizer-derived WOX5 signal maintains root columella stem cells through chromatin-mediated repression of CDF4 expression. Dev Cell 33, 576-588. doi: 10.1016/j.devcel.2015.04.024

Pontvianne, F., Blevins, T., and Pikaard, C. S. (2010). Arabidopsis histone lysine methyltransferases. Adv. Bot. Res. 53, 1-22. doi: 10.1016/S0065-2296(10)53001-5

Ren, H., Santner, A., del Pozo, J. C., Murray, J. A., and Estelle, M. (2008). Degradation of the cyclin-dependent kinase inhibitor KRP1 is regulated by two different ubiquitin E3 ligases. Plant J. 53, 705-716. doi: 10.1111/j.1365-313X.2007.03370.x

Sang, Y., Silva-Ortega, C. O., Wu, S., Yamaguchi, N., Wu, M. F., Pfluger, J., et al. (2012). Mutations in two non-canonical Arabidopsis SWI2/SNF2 chromatin remodeling ATPases cause embryogenesis and stem cell maintenance defects. Plant J. 72, 1000-1014. doi: 10.1111/tpj.12009

Scheres, B. J. G., Wolkenfelt, H., Willemsen, V., Terlouw, M., Lawson, E., Dean, C., et al. (1994). Embryonic origin of the Arabidopsis primary root and root meristem initials. Development 120, 2475-2487.

Schubert, D., Primavesi, L., Bishopp, A., Roberts, G., Doonan, J., Jenuwein, T., et al. (2006). Silencing by plant Polycomb-group genes requires dispersed trimethylation of histone $\mathrm{H3}$ at lysine 27. EMBO J. 25, 4638-4649. doi: 10.1038/s.emboj.7601311

Schuettengruber, B., and Cavalli, G. (2009). Recruitment of polycomb group complexes and their role in the dynamic regulation of cell fate choice. Development 136, 3531-3542. doi: 10.1242/dev.033902

Schuettengruber, B., Chourrout, D., Vervoort, M., Leblanc, B., and Cavalli, G. (2007). Genome regulation by polycomb and trithorax proteins. Cell 128, 735-745. doi: 10.1016/j.cell.2007.02.009

Shahbazian, M. D., and Grunstein, M. (2007). Functions of site-specific histone acetylation and deacetylation. Annu. Rev. Biochem. 76, 75-100. doi: 10.1146/annurev.biochem.76.052705.162114

Shan, Q., Wang, Y., Li, J., Zhang, Y., Chen, K., Liang, Z., et al. (2013). Targeted genome modification of crop plants using a CRISPR-Cas system. Nat. Biotechnol. 31, 686-688. doi: 10.1038/nbt.2650

Suzuki, M., Wang, H. H., and McCarty, D. R. (2007). Repression of the leafy cotyledon 1/B3 regulatory network in plant embryo development by VP1/ABSCISIC acid insensitive 3-like B3 genes. Plant Physiol. 143, 902-911. doi: 10.1104/pp.106.092320

Tanaka, M., Kikuchi, A., and Kamada, H. (2008). The Arabidopsis histone deacetylases HDA6 and HDA19 contribute to the repression of embryonic properties after germination. Plant Physiol. 146, 149-161. doi: 10.1104/pp.107.111674

Verstraeten, I., Schotte, S., and Geelen, D. (2014). Hypocotyl adventitious root organogenesis differs from lateral root development. Front. Plant Sci. 5:495. doi: $10.3389 /$ fpls.2014.00495

Vlachonasios, K. E., Thomashow, M. F., and Triezenberg, S. J. (2003). Disruption mutations of ADA2b and GCN5 transcriptional adaptor genes dramatically affect Arabidopsis growth, development, and gene expression. Plant Cell 15, 626-638. doi: 10.1105/tpc.007922

Wang, Y., Wang, D., Gan, T., Liu, L., Long, W., Wang, Y., et al. (2016). CRL6, a member of the CHD protein family, is required for crown root development in rice. Plant Physiol. Biochem. 105, 185-194. doi: 10.1016/j.plaphy.2016.04.022

Wanke, D., Hohenstatt, M. L., Dynowski, M., Bloss, U., Hecker, A., Elgass, K., et al. (2011). Alanine zipper-like coiled-coil domains are necessary for homotypic dimerization of plant GAGA-factors in the nucleus and nucleolus. PLOS ONE 6:e16070. doi: 10.1371/journal.pone.0016070

Xu, C. R., Liu, C., Wang, Y. L., Li, L. C., Chen, W. Q., Xu, Z. H., et al. (2005). Histone acetylation affects expression of cellular patterning genes in 
the Arabidopsis root epidermis. Proc. Natl. Acad. Sci. U.S.A. 102, 14469-14474. doi: 10.1073/pnas.0503143102

$\mathrm{Xu}$, L., and Shen, W. H. (2008). Polycomb silencing of KNOX genes confines shoot stem cell niches in Arabidopsis. Curr. Biol. 18, 1966-1971. doi: 10.1016/j.cub.2008, 11.019

Yang, C., Bratzel, F., Hohmann, N., Koch, M., Turck, F., and Calonje, M. (2013). VAL- and AtBMI1-mediated H2Aub initiate the switch from embryonic to postgerminative growth in Arabidopsis. Curr. Biol. 23, 1324-1329. doi: 10.1016/j.cub.2013. 05.050

Yang, S., Li, C., Zhao, L., Gao, S., Lu, J., Zhao, M., et al. (2015). The arabidopsis SWI2/SNF2 chromatin remodeling ATPase BRAHMA targets directly to PINs and is required for root stem cell niche maintenance. Plant Cell 27, 1670-1680. doi: 10.1105/tpc.15.00091

Yao, X., Feng, H., Yu, Y., Dong, A., and Shen, W. H. (2013). SDG2mediated H3K4 methylation is required for proper Arabidopsis root growth and development. PLOS ONE 8:e56537. doi: 10.1371/journal.pone.0 056537

Yuan, W., Luo, X., Li, Z., Yang, W., Wang, Y., Liu, R., et al. (2016). A cis cold memory element and a trans epigenome reader mediate Polycomb silencing of FLC by vernalization in Arabidopsis. Nat. Genet. 48, 1527-1534. doi: $10.1038 /$ ng.3712

Zhang, H., Lang, Z., and Zhu, J. K. (2018). Dynamics and function of DNA methylation in plants. Nat. Rev. Mol. Cell Biol. 19, 489-506. doi: 10.1038/s41580-018-0016-Z

Zhang, J., Lai, J., Wang, F., Yang, S., He, Z., Jiang, J., et al. (2017). A SUMO ligase AtMMS21 regulates the stability of the chromatin remodeler BRAHMA in root development. Plant Physiol. 173, 1574-1582. doi: 10.1104/pp.17. 00014
Zhang, Y., Jiao, Y., Liu, Z., and Zhu, Y. X. (2015). ROW1 maintains quiescent centre identity by confining WOX5 expression to specific cells. Nat. Commun. 6:6003. doi: $10.1038 /$ ncomms7003

Zhang, Y., Zheng, L., Hong, J. H., Gong, X., Zhou, C., Perez-Perez, J. M., et al. (2016). TOPOISOMERASElalpha acts through two distinct mechanisms to regulate stele and columella stem cell maintenance. Plant Physiol. 171, 483-493. doi: 10.1104/pp.15.01754

Zhou, S., Jiang, W., Long, F., Cheng, S., Yang, W., Zhao, Y., et al. (2017). Rice homeodomain protein WOX11 recruits a histone acetyltransferase complex to establish programs of cell proliferation of crown root meristem. Plant Cell 29, 1088-1104. doi: 10.1105/tpc.16.00908

Zhou, Y., Tan, B., Luo, M., Li, Y., Liu, C., Chen, C., et al. (2013). HISTONE DEACETYLASE19 interacts with HSL1 and participates in the repression of seed maturation genes in Arabidopsis seedlings. Plant Cell 25, 134-148. doi: 10.1105/tpc.112.096313

Zhu, J., Ingram, P. A., Benfey, P. N., and Elich, T. (2011). From lab to field, new approaches to phenotyping root system architecture. Curr. Opin. Plant Biol. 14, 310-317. doi: 10.1016/j.pbi.2011.03.020

Conflict of Interest Statement: The authors declare that the research was conducted in the absence of any commercial or financial relationships that could be construed as a potential conflict of interest.

Copyright (C) 2018 Chen, Huang, Jiang and Si. This is an open-access article distributed under the terms of the Creative Commons Attribution License (CC BY). The use, distribution or reproduction in other forums is permitted, provided the original author(s) and the copyright owner(s) are credited and that the original publication in this journal is cited, in accordance with accepted academic practice. No use, distribution or reproduction is permitted which does not comply with these terms. 